\title{
Práticas de enfermeiras na assistência ao parto no Brasil: revisão de literatura
}

\author{
Nurses practices in childbirth care in Brazil: \\ literature review
}

\section{Laís da Silva Bispo' 1 (1) Fernanda Sampaio Novaes ${ }^{2}$ (1) Bárbara Angélica Gómez Pérez ${ }^{3}$ (1)}

${ }^{1}$ Autora para correspondência. Escola Bahiana de Medicina e Saúde Pública (Salvador). Bahia, Brasil. laisbispo16.1@bahiana.edu.br ${ }^{2}$ Escola Bahiana de Medicina e Saúde Pública (Salvador). Bahia, Brasil. fernandanovaes16.1@bahiana.edu.br ${ }^{3}$ Escola Bahiana de Medicina e Saúde Pública (Salvador), Universidade Estadual da Bahia (Salvador). Salvador, Bahia, Brasil. bagperez@bahiana.edu.br

RESUMO | OBJETIVO: Descrever e discutir a produção científica acerca da prática de enfermeiras na assistência ao parto. MÉTODO: Foi realizada uma revisão de literatura integrativa utilizando publicações disponíveis. A busca dos artigos ocorreu nas bases de dados LILACS, BDENF, Portal de periódicos CAPES, Biblioteca Eletrônica Científica Online SCIELO no período de 2014 a 2019, sendo selecionados e analisados 14 estudos. Para pesquisa foi utilizado os descritores "saúde da mulher", "parto humanizado", "parto normal", "enfermeiras obstétricas", "humanização da assistência" com o operador booleano AND no final de cada descritor. Os critérios de inclusão utilizados foram artigos originais e de revisão, publicados na íntegra, na língua portuguesa em periódicos nacionais. RESULTADOS: Emergiram duas categorias de análise: Prática das enfermeiras acerca das boas práticas da assistência ao parto e nascimento e fatores que interferem no trabalho de parto das parturientes. CONSIDERAÇõES FINAIS: Verificou-se uma adesão às boas práticas de atenção ao parto e nascimento, como o uso de métodos não farmacológicos no manejo da dor, presença do acompanhante, dentre outros. No entanto, também foi observado que as mulheres são colocadas em um lugar passivo e ficam expostas devido a uma estrutura inadequada e a falta de recursos materiais.

DESCRITORES: Saúde da mulher. Parto humanizado. Parto normal. Enfermeiras obstétricas. Humanização da assistência.
ABSTRACT | OBJECTIVE: To describe and discuss the scientific production about the practice of nurses in childbirth care. METHOD: An integrative literature review was performed using available publications. The search for the articles took place in the databases LILACS, BDENF, Portal of CAPES journals, SCIELO Online Scientific Electronic Library from 2014 to 2019 , with 14 studies being selected and analyzed. The research used the descriptors "women's health", "humanized childbirth", "normal birth", "obstetric nurses", "humanization of assistance" with the Boolean operator AND at the end of each descriptor. The inclusion criteria used were original and review articles, published in full, in Portuguese in national journals. RESULTS: Two categories of analysis emerged: Nurses' practices regarding good practices in childbirth and birth care and factors that interfere in the labor of parturients. FINAL CONSIDERATIONS: There was an adherence to good practices in childbirth and birth care, such as the use of nonpharmacological methods in pain management, the presence of a companion, among others. However, it was also observed that women are placed in a passive place and are exposed due to an inadequate structure and the lack of material resources.

DESCRIPTORS: Women's health. Humanized birth. Normal birth. Obstetric nurses. Humanization of assistance. 


\section{Introdução}

A humanização das práticas e do modelo assistencial à saúde vem sendo motivo de discussão há várias décadas em todo mundo e, nos últimos anos, tem sido um tema constante em diversos estudos científicos nacionais, sendo notória a importância de políticas públicas voltadas para essa área'

Com relação ao parto e puerpério, o conceito de humanização pode ter diversos significados como humanização da relação entre profissionais e usuários ou a qualidade dos cuidados com todo o processo do parto'. O intuito da humanização é privilegiar o bemestar da mulher e do bebê considerando os aspectos fisiológicos, psicológicos e sociais, caracterizado pelo contínuo acompanhamento de gestação e parturição². É fundamentada em dois aspectos principais: o dever das unidades de saúde e de seus profissionais em receber a mulher, seus familiares e o recém-nascido com dignidade, atitude ética e solidária; e adotar medidas que beneficie o acompanhamento do parto e do nascimento, evitando intervenções desnecessárias ${ }^{2,3}$.

Dentro desta ótica, foi evidenciado que a enfermeira propicia percepção e assistência com ampla e objetiva perspicácia, relacionada ao desenvolvimento de técnicas e procedimentos, além de visão subjetiva fundamentada em criatividade, sensibilidade e intuição para cuidar de outro ser ${ }^{4}$. É importante que este profissional valorize as queixas, expressões e sentimentos relatados pelas mulheres, o que irá influenciar na elaboração de um plano de cuidado centrado na pessoa, atendendo suas particularidades, envolvendo-as no cuidado o que irá garantir uma assistência de qualidade, individualizada e integral ${ }^{5-7}$.

O guia de recomendações da assistência ao parto normal8-9 ${ }^{8-9}$ criado pela Organização Mundial de Saúde (OMS) em 1996, teve como intuito minimizar práticas desnecessárias e inapropriadas ao parto, visando a implementação do parto humanizado nos serviços de saúde. Baseou-se em evidências cientificas e classificou quatro categorias: práticas que são nitidamente úteis e que deveriam ser estimuladas; práticas claramente prejudiciais ou ineficazes e que deveriam ser eliminadas; práticas com evidência insatisfatórias para desenvolver uma recomendação e que deveriam ser usadas com precaução; e práticas frequentemente utilizadas de forma inapropriadas.
No ano 2000, foi instituída pelo Ministério da Saúde, o Programa de Humanização no Pré-natal e Nascimento (PHPN) embasado nos preceitos de que a humanização da assistência é a condição primária para o acompanhamento apropriado do parto e do puerpério ${ }^{2}$. Após onze anos foi lançado pelo Governo Federal, o plano Rede Cegonha, com o intuito de assegurar às mulheres não só saúde, mas também qualidade de vida e bem-estar durante a gestação, parto, pós-parto e o desenvolvimento da criança até os primeiros dois anos de vida ${ }^{3}$. Tanto o programa quanto o plano têm como objetivo principal reduzir as taxas de morbimortalidade materna e infantil ${ }^{2,3}$.

Nessa perspectiva, foi comprovado que os avanços na obstetrícia favoreceram o declínio dos índices de morbimortalidade materna e perinatais no mundo. Ainda assim, as mulheres e recém-nascido (RN) ficam vulneráveis a intervenções precipitadas e ou desnecessárias, sendo que as mesmas só deveriam ser adotadas se houvesse realmente necessidade ${ }^{10}$.

É evidente que a prática em obstetrícia tem passado por modificações relevantes nos últimos 20-30 anos, devido tanto às opiniões públicas e de consumidores do serviço de saúde, quanto à chegada de novas evidências cientificas, dando maior relevância a promoção e o resgate das características naturais e fisiológicas do parto e nascimento ${ }^{10}$.

Nota-se também que as parturientes colaboram passivamente para a representação do modelo biomédico e intervencionista, especialmente quando admitem a conduta exigida. Há A falta de compreensão dessas sobre seu corpo, sobre o processo do parto e suas crenças torna-as convicta de que dependem do profissional para que o seu parto aconteça. Nesta perspectiva muitos profissionais colaboram para colocá-las em situação de vulnerabilidade através do desconhecimento sobre o tipo de assistência que deveria ser ofertada, os direitos das parturientes e as diretrizes trazidas no PHPN ${ }^{11}$.

Durante o processo de trabalho de parto e parto, as mulheres valorizam os profissionais como aqueles indivíduos encarregados por retirar sua dor e na fugacidade de solucionar o seu sofrimento ele determina e elas acatam, não despertando ao menos algum interesse em saber quem é essa pessoa ${ }^{11}$. 
Neste âmbito, partindo-se do pressuposto que as boas práticas a assistência ao parto devem ser aplicadas para diminuir intervenções desnecessárias, tornando o processo de parto único, humanizado e individualizado para cada mulher, podendo ter causas irreparáveis quando não aplicadas.

A relevância deste estudo concentra-se no grande desafio de colocar em evidencia a assistência humanizada ao parto em nosso país, pois demanda na mudança de paradigma no que diz respeito à atitude dos profissionais de saúde que assistem as parturientes e pela importância de se aprofundar a discussão sobre a violência obstétrica e suas implicações na história de vida e saúde das mulheres.

Esta pesquisa teve como objetivo descrever e discutir a produção científica acerca da prática de enfermeiras na assistência ao parto.

\section{Método}

Trata-se de uma revisão de literatura do tipo integrativa a qual teve como propósito reunir e sintetizar o conhecimento científico já produzido sobre o tema pesquisado, permitindo o rastreio, avaliação, sintetização de inúmeros fundamentos disponíveis para a sua incorporação na prática, contribuindo para o aprofundamento do conhecimento ${ }^{12}$.

As buscas das publicações foram realizadas no portal de Biblioteca Virtual em Saúde (BVS) nas bases de dados BDENF, LILACS, no mês de novembro de 2019 (Quadro 1). Também foram utilizados: Portal de periódicos CAPES, Biblioteca Eletrônica Científica Online SCIELO. Para pesquisa foram utilizados os descritores "saúde da mulher", "parto humanizado", "parto normal", "enfermeiras obstétricas", "humanização da assistência" com o operador booleano AND no final de cada descritor. Como critérios de inclusão utilizou-se os artigos originais e de revisão, publicados na integra na língua portuguesa, em periódicos nacionais no período de 2014 a 2019.

Para a seleção final dos artigos inicialmente foram lidos os títulos, resumos e objetivos e os artigos na integra.

Fluxograma 1. Descrição da seleção dos artigos
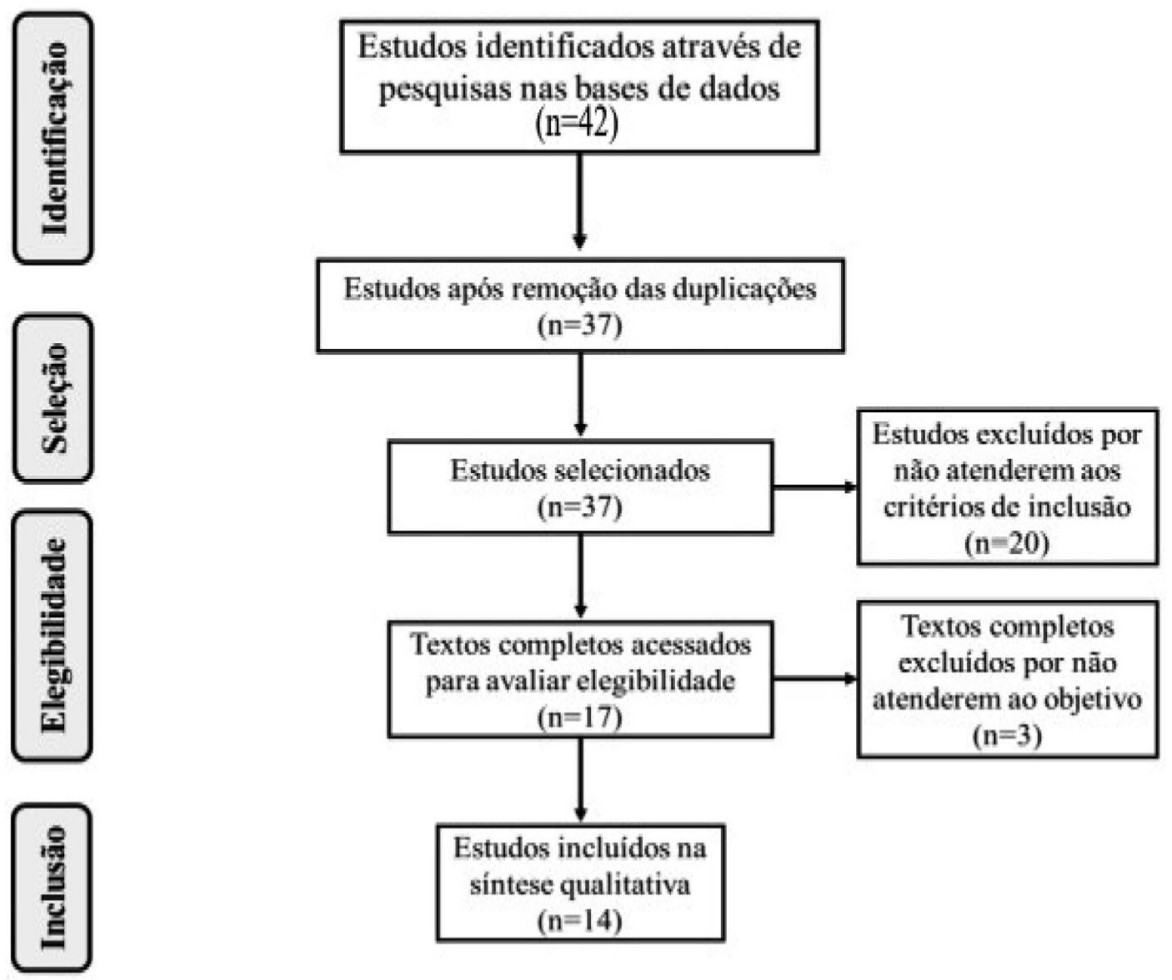

Fonte: As autoras (2020). 
Foram encontrados no total 42 artigos, excluindo 5 artigos pois estavam duplicados, sendo então selecionados 37 artigos. Destes, 20 foram excluídos porque não atenderam aos critérios de inclusão e 3 estudos também foram excluídos por não atenderam ao objetivo da revisão. Sendo assim, foram analisados na síntese qualitativa 14 artigos, que serão apresentados no Quadro 1. Além dos artigos, foram utilizados para a discussão, 4 manuais do Ministério da Saúde e 2 da Organização Mundial de Saúde, além da legislação federal da Lei do Acompanhante, encontrados a partir de busca manual.
Após as leituras dos artigos, os resultados dos autores foram confrontados e retidos as concordâncias e discordâncias para melhor entendimento da temática escolhida.

\section{Resultados e discussão}

Para melhor entendimento e discussão dos resultados encontrados construiu-se um quadro descritivos (Quadro 1) com os principais dados dos artigos selecionados após a execução da metodologia proposta.

Quadro 1. Descrição dos artigos coletados

\begin{tabular}{|c|c|c|c|c|c|}
\hline AUTOR & TÍTULO & ANO & REVISTA & $\begin{array}{l}\text { TIPO DE } \\
\text { ESTUDO }\end{array}$ & OBJETIVO \\
\hline $\begin{array}{c}\text { Duarte MR, } \\
\text { Alves VH, } \\
\text { Rodrigues DP, } \\
\text { Souza KV, } \\
\text { Pereira AV, } \\
\text { Pimentel MM. }\end{array}$ & $\begin{array}{l}\text { Tecnologias do } \\
\text { cuidado na } \\
\text { enfermagem } \\
\text { obstétrica: } \\
\text { contribuição para o } \\
\text { parto e nascimento }\end{array}$ & 2019 & $\begin{array}{l}\text { Cogitare } \\
\text { Enfermagem }\end{array}$ & $\begin{array}{l}\text { Estudo } \\
\text { descritivo, } \\
\text { exploratório e } \\
\text { qualitativo }\end{array}$ & $\begin{array}{l}\text { Identificar as tecnologias do } \\
\text { cuidado utilizadas por } \\
\text { enfermeiras obstétricas em um } \\
\text { Centro de Parto Normal }\end{array}$ \\
\hline $\begin{array}{l}\text { Carvalho EMP } \\
\text { de, Amorim FF, } \\
\text { Santana LA, } \\
\text { Göttems LBD }\end{array}$ & $\begin{array}{c}\text { Avaliação das boas } \\
\text { práticas de atenção } \\
\text { ao parto por } \\
\text { profissionais dos } \\
\text { hospitais públicos do } \\
\text { Distrito Federal, Brasil }\end{array}$ & 2019 & $\begin{array}{l}\text { Ciência \& } \\
\text { Saúde } \\
\text { Coletiva }\end{array}$ & $\begin{array}{l}\text { Estudo } \\
\text { transversal, } \\
\text { do tipo } \\
\text { inquérito }\end{array}$ & $\begin{array}{c}\text { Avaliar a adesão às boas práticas } \\
\text { de atenção ao parto e nascimento, } \\
\text { entre médicos, enfermeiros e } \\
\text { residentes dos programas de } \\
\text { residência em obstetrícia, dos } \\
\text { hospitais públicos do Distrito } \\
\text { Federal (DF) }\end{array}$ \\
\hline $\begin{array}{l}\text { Santana AT, } \\
\text { Dias R, } \\
\text { Felzemburgh M, } \\
\text { Couto TM. }\end{array}$ & $\begin{array}{l}\text { Atuação de } \\
\text { enfermeiras } \\
\text { residentes em } \\
\text { obstetrícia na } \\
\text { assistência ao parto }\end{array}$ & 2019 & $\begin{array}{l}\text { Revista } \\
\text { Brasileira } \\
\text { Saúde } \\
\text { Materna } \\
\text { Infantil }\end{array}$ & $\begin{array}{l}\text { Estudo } \\
\text { transversal } \\
\text { descritivo e } \\
\text { quantitativo }\end{array}$ & $\begin{array}{l}\text { Descrever as boas práticas de } \\
\text { atenção ao parto e as } \\
\text { intervenções obstétricas } \\
\text { realizadas por enfermeiras } \\
\text { residentes em obstetrícia, durante } \\
\text { a assistência ao parto de risco } \\
\text { obstétrico habitual, em uma } \\
\text { maternidade pública de Salvador. }\end{array}$ \\
\hline $\begin{array}{c}\text { Ramos WMA, } \\
\text { Aguiar BGC, } \\
\text { Conrad D, Pinto } \\
\text { CB, Mussumeci } \\
\text { PA. }\end{array}$ & $\begin{array}{c}\text { Contribuição da } \\
\text { enfermeira obstétrica } \\
\text { nas boas práticas da } \\
\text { assistência ao parto e } \\
\text { nascimento }\end{array}$ & 2018 & $\begin{array}{l}\text { Cuidado é } \\
\text { fundamental }\end{array}$ & $\begin{array}{c}\text { Estudo } \\
\text { documental }\end{array}$ & $\begin{array}{c}\text { Identificar as boas práticas } \\
\text { desenvolvidas pela Enfermeira } \\
\text { Obstétrica em uma Maternidade } \\
\text { Municipal do Rio de Janeiro e } \\
\text { analisar a assistência das } \\
\text { Enfermeiras Obstétricas nas Boas } \\
\text { Práticas no momento do parto. }\end{array}$ \\
\hline $\begin{array}{c}\text { Feijão LBV, } \\
\text { Boeckmann } \\
\text { LMM, Melo MC }\end{array}$ & $\begin{array}{l}\text { Conhecimento de } \\
\text { enfermeiras } \\
\text { residentes acerca das } \\
\text { boas práticas na } \\
\text { atenção ao parto }\end{array}$ & 2017 & $\begin{array}{l}\text { Enfermagem } \\
\text { em Foco }\end{array}$ & $\begin{array}{c}\text { Estudo } \\
\text { descritivo } \\
\text { exploratório e } \\
\text { qualitativo }\end{array}$ & $\begin{array}{l}\text { Conhecer as percepções, vivências } \\
\text { e experiências de residentes de } \\
\text { Enfermagem Obstétrica acerca da } \\
\text { humanização da assistência } \\
\text { pautada nas boas práticas de } \\
\text { atenção ao parto de risco habitual }\end{array}$ \\
\hline $\begin{array}{l}\text { Pedroso CNLS, } \\
\text { López LC. }\end{array}$ & $\begin{array}{c}\text { À margem da } \\
\text { humanização? } \\
\text { Experiências de parto } \\
\text { de usuárias de uma } \\
\text { maternidade pública } \\
\text { de Porto Alegre-RS }\end{array}$ & 2017 & $\begin{array}{l}\text { Physis: } \\
\text { Revista de } \\
\text { Saúde } \\
\text { Coletiva }\end{array}$ & $\begin{array}{c}\text { Estudo } \\
\text { exploratório e } \\
\text { qualitativo }\end{array}$ & $\begin{array}{c}\text { Analisar o cenário obstétrico } \\
\text { brasileiro }\end{array}$ \\
\hline
\end{tabular}


Quadro 1. Descrição dos artigos coletados

\begin{tabular}{|c|c|c|c|c|c|}
\hline AUTOR & TÍTULO & ANO & REVISTA & $\begin{array}{l}\text { TIPO DE } \\
\text { ESTUDO }\end{array}$ & OBJETIVO \\
\hline $\begin{array}{l}\text { Silva RDM da, } \\
\text { Lima LSV, } \\
\text { Aquino DMF, } \\
\text { Silva LXL, Silva } \\
\text { AB, Vicente CD. }\end{array}$ & $\begin{array}{l}\text { Inserção do pai nas } \\
\text { maternidades } \\
\text { municipais do Recife: } \\
\text { opinião dos técnicos e } \\
\text { auxiliares de } \\
\text { enfermagem. }\end{array}$ & 2017 & $\begin{array}{c}\text { Enfermagem } \\
\text { em Foco }\end{array}$ & $\begin{array}{c}\text { Estudo } \\
\text { quantitativo }\end{array}$ & $\begin{array}{l}\text { Descrever a opinião dos técnicos e } \\
\text { auxiliares de enfermagem do } \\
\text { centro obstétrico e alojamento } \\
\text { conjunto, sobre a inserção do pai } \\
\text { como acompanhante no processo } \\
\text { parturitivo, nas maternidades } \\
\text { municipais do Recife }\end{array}$ \\
\hline $\begin{array}{l}\text { Andrade LO de, } \\
\text { Felix ESP, Souza } \\
\text { FS, Gomes LOS, } \\
\text { Boery RNSO. } \\
\end{array}$ & $\begin{array}{c}\text { Práticas dos } \\
\text { profissionais de } \\
\text { enfermagem diante } \\
\text { do parto humanizado }\end{array}$ & 2017 & $\begin{array}{l}\text { Revista } \\
\text { enfermagem } \\
\text { UFPE online }\end{array}$ & $\begin{array}{l}\text { Estudo } \\
\text { descritivo e } \\
\text { qualitativo }\end{array}$ & $\begin{array}{c}\text { Conhecer como são desenvolvidas } \\
\text { as práticas de humanização } \\
\text { durante o trabalho de parto }\end{array}$ \\
\hline $\begin{array}{l}\text { Dulfe PAM, } \\
\text { Barcellos JG, } \\
\text { Alves VH, } \\
\text { Rodrigues DP, } \\
\text { Pereira AV, Da } \\
\text { Silva AG. } \\
\end{array}$ & $\begin{array}{c}\text { A assistência } \\
\text { obstétrica ao parto e } \\
\text { nascimento na } \\
\text { percepção das } \\
\text { mulheres }\end{array}$ & 2017 & $\begin{array}{l}\text { Revista } \\
\text { enfermagem } \\
\text { UFPE online }\end{array}$ & $\begin{array}{l}\text { Revisão } \\
\text { integrativa }\end{array}$ & $\begin{array}{l}\text { Analisar a produção científica } \\
\text { sobre a percepção das mulheres a } \\
\text { respeito da assistência do } \\
\text { processo parturitivo. }\end{array}$ \\
\hline $\begin{array}{l}\text { Andrade LFB } \\
\text { de, Rodrigues } \\
\text { QP, Silva RCV. }\end{array}$ & $\begin{array}{l}\text { Boas Práticas na } \\
\text { atenção obstétrica e } \\
\text { sua interface com a } \\
\text { humanização da } \\
\text { assistência }\end{array}$ & 2017 & $\begin{array}{c}\text { Revista } \\
\text { enfermagem } \\
\text { UERJ }\end{array}$ & $\begin{array}{c}\text { Estudo } \\
\text { descritivo e } \\
\text { quantitativo }\end{array}$ & $\begin{array}{c}\text { Analisar as boas práticas adotadas } \\
\text { na atenção à mulher e ao recém- } \\
\text { nascido, em uma maternidade } \\
\text { pública baiana, apoiada pela Rede } \\
\text { Cegonha. }\end{array}$ \\
\hline $\begin{array}{c}\text { Oliveira JDG, } \\
\text { Campo TNC, } \\
\text { Souza FMLC, } \\
\text { Davim RMB, } \\
\text { Dantas JC. }\end{array}$ & $\begin{array}{c}\text { Percepção de } \\
\text { enfermeiros obstetras } \\
\text { na assistência à } \\
\text { parturiente }\end{array}$ & 2016 & $\begin{array}{l}\text { Revista } \\
\text { Enfermagem } \\
\text { UFPE online }\end{array}$ & $\begin{array}{l}\text { Estudo } \\
\text { descritivo e } \\
\text { qualitativa }\end{array}$ & $\begin{array}{l}\text { Conhecer a percepção do } \\
\text { enfermeiro obstetra na } \\
\text { assistência à parturiente. }\end{array}$ \\
\hline $\begin{array}{l}\text { Medeiros RMK, } \\
\text { Teixeira RC, } \\
\text { Nicolini AB, } \\
\text { Alvares AS, } \\
\text { Corrêa ÁCP, } \\
\text { Martins DP. } \\
\end{array}$ & $\begin{array}{c}\text { Cuidados } \\
\text { humanizados: a } \\
\text { inserção de } \\
\text { enfermeiras } \\
\text { obstétricas em um } \\
\text { hospital de ensino } \\
\end{array}$ & 2016 & $\begin{array}{l}\text { Revista } \\
\text { Brasileira de } \\
\text { Enfermagem }\end{array}$ & $\begin{array}{l}\text { Estudo } \\
\text { transversal, } \\
\text { descritivo e } \\
\text { quantitativo }\end{array}$ & $\begin{array}{c}\text { Analisar a assistência prestada em } \\
\text { uma unidade de Pré- } \\
\text { parto/Parto/Pós-parto (PPP) de } \\
\text { um hospital de ensino após a } \\
\text { inserção de enfermeiras } \\
\text { obstétricas }\end{array}$ \\
\hline $\begin{array}{l}\text { Souza SRRK, } \\
\text { Gualda DMR. }\end{array}$ & $\begin{array}{l}\text { A experiência da } \\
\text { mulher e de seu } \\
\text { acompanhante no } \\
\text { parto em uma } \\
\text { maternidade pública } \\
\end{array}$ & 2016 & $\begin{array}{c}\text { Texto } \\
\text { Contexto } \\
\text { Enfermagem }\end{array}$ & $\begin{array}{l}\text { Estudo } \\
\text { qualitativo }\end{array}$ & $\begin{array}{c}\text { Conhecer a experiência de } \\
\text { mulheres e de seus } \\
\text { acompanhantes no processo de } \\
\text { parto }\end{array}$ \\
\hline $\begin{array}{l}\text { Pérez BAG, } \\
\text { Oliveira EV, } \\
\text { Lago MS. }\end{array}$ & $\begin{array}{c}\text { Percepções de } \\
\text { puérperas vítimas de } \\
\text { violência institucional } \\
\text { durante o trabalho de } \\
\text { parto e parto }\end{array}$ & 2015 & $\begin{array}{c}\text { Revista } \\
\text { Enfermagem } \\
\text { Contemporâ } \\
\text { nea }\end{array}$ & $\begin{array}{l}\text { Revisão } \\
\text { integrativa }\end{array}$ & $\begin{array}{c}\text { Analisar os resultados de } \\
\text { pesquisas sobre as percepções de } \\
\text { puérperas vítimas de violência } \\
\text { institucional no seu trabalho de } \\
\text { parto e parto, relacionando com } \\
\text { poder e gênero. }\end{array}$ \\
\hline
\end{tabular}

Fonte: As autoras (2020). 
A partir dos estudos encontrados, emergiram duas categorias de análise: Prática das enfermeiras acerca das boas práticas da assistência ao parto e nascimento e Fatores que interferem no trabalho de parto e parto das parturientes ( $\mathrm{O}$ acompanhante, Estrutura física e recursos materiais, Relações de poder e Uso dos métodos não farmacológicos de alívio da dor).

\section{Prática das enfermeiras acerca das boas práticas da assistência ao parto e nascimento}

A atuação da enfermeira obstétrica no acompanhamento ao parto de risco habitual é de fundamental importância para a segurança e qualidade da assistência prestada ao binômio mãe-filho-pai-família, além de garantir um cuidado provido de respeito, acolhimento, condutas baseadas em evidências e conhecimentos científicos que irão favorecer um parto fisiológico e natural sem necessidade de intervenções médicas e/ou farmacológicas 4 .

Sendo assim, é necessário que os profissionais de saúde respeitem os desejos e as escolhas das parturientes, intervindo quando for realmente necessário e com o consentimento prévio das mesmas, entendendo que a mulher é a protagonista do seu parto e que eles devem estar disponíveis para assisti-las e auxiliá-las.

Sabe-se que o trabalho das enfermeiras se baseia na fisiologia do trabalho de parto e cada vez mais tem utilizado tecnologias de cuidados que são benéficas para as parturientes e também para o desenvolvimento e saúde do recém-nascido, tais como: adoção de medidas que proporcionam o alivio da dor com métodos não farmacológicos; livre posicionamento; clampeamento tardio de cordão umbilical; contato pele a pele estimulando o vínculo do binômio mãefilho; presença e participação do acompanhante no trabalho de parto e parto e amamentação precoce ${ }^{4,7}$.

O guia de recomendações do parto normal8 instituiu condutas que são consideradas boas práticas da humanização na assistência ao parto e nascimento que tem como objetivo normalizar a assistência dos profissionais de saúde perante das parturientes, reduzir os índices de morbimortalidade materna e neonatal e assegurar o nascimento seguro.

Neste sentido, o conhecimento técnico e científico das enfermeiras sobre as boas práticas é de fundamental importância para execução de um trabalho de parto humanizado, sendo necessário saber em qual fase do trabalho de parto cada método não farmacológico pode ser usado, ouvindo e respeitando os desejos e limites de cada mulher. Assim, o apoio, segurança e confiança passados pelas enfermeiras e acompanhantes nesse momento são alicerces e facilitadores para o protagonismo da mulher, tornando esse trabalho de parto mais curto e com menor inclusão de métodos farmacológicos e partos operatórios ${ }^{4,13,14}$.

Foi possível evidenciar uma lacuna na maioria dos estudos analisados acerca das práticas dos profissionais de saúde sobre a nutrição da mulher durante o trabalho de parto, sendo só evidenciado no estudo de Pedroso ${ }^{18}$ onde referiu que as parturientes recebem uma alimentação adequada durante o trabalho de parto.

Sendo assim, destaca-se a importância da nutrição da mulher, pois este momento requer uma maior quantidade de energia por não se prever a duração do processo de trabalho de parto e este ser extremamente desgastante, podendo trazer danos materno-fetal ${ }^{15}$.

Sobretudo, observa-se ainda no que diz respeito às boas práticas que diversos estudos abordam outros aspectos como a monitorização fetal durante o trabalho de parto, o clampeamento tardio do cordão umbilical, o estimulo do contato pele a pele entre a mãe e o bebê logo ao nascer, além da importância de incentivar o aleitamento precoce, sendo que todas essas práticas fazem parte da hora dourada que é a primeira hora do recém-nascido, itens que tangem as boas práticas da humanização no parto e nascimento

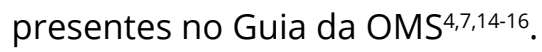

Reflete-se que é essencial, a comunicação entre as enfermeiras e parturientes, a escuta ativa e qualificada para que as informações fidedignas sejam passadas. Neste sentido, irão acalmar a mulher em todo o processo de parto, sendo importante valorizar as queixas e as dores da mulher, suas expressões verbais e não-verbais, esclarecer os questionamentos, explicar os procedimentos, seus benefícios e malefícios e só realiza-los a partir do seu consentimento, assegurando um tratamento digno e respeitoso, centrado nas necessidades da mulher e do bebê ${ }^{15}$.

Nota-se a importância dos profissionais de saúde estarem atentos as necessidades das parturientes, criando um vínculo humano e integral que valorize as particularidades de cada usuária, que suas condutas sejam baseadas no que é preconizado pela OMS e pela PHPN, garantindo uma assistência humanizada em um local 
adequado para que possam ser ouvidas, acolhidas e respeitas sobre suas escolhas e sentimentos ${ }^{5,17,18 .}$

Neste sentido destaca-se a relevância do protagonismo das mulheres no seu parto e para que isso aconteça é necessário que elas sejam respeitadas em todo seu processo, evitando práticas e procedimentos invasivos desnecessários, sendo as enfermeiras também responsáveis por prestar essa assistência humanizada propiciando uma maior segurança e autonomia da mulher no processo de parto ${ }^{19}$.

\section{Fatores que interferem no trabalho de parto e parto das parturientes}

Nesta categoria foram relacionados os principais fatores que foram encontrados como intervenientes no trabalho de parto e parto, destacando-se a importância da presença do acompanhante, interferência da estrutura física e recursos materiais no processo de parto, as relações de poder que acontecem para com as parturientes e os benefícios do uso das terapias não farmacológicas.

\section{O Acompanhante}

Instituída em abril de 2005, a Lei Federal ${ }^{\circ} 11.108$, popularmente conhecida como Lei do Acompanhante, estabelece que os serviços de saúde do SUS, tanto da sua própria rede, quanto da conveniada, são obrigados a autorizar à gestação o direito ao acompanhante durante todo o trabalho de parto, parto e pós-parto, sendo o mesmo indicado pela gestante, podendo ser o pai do seu filho, atual parceiro, mãe ou pai da mesma, amigo (a), ou qualquer outra pessoa da sua escolha ${ }^{20}$.

Tornou-se evidente que a presença do acompanhante no processo de parto proporciona bem-estar físico e emocional à mulher, transferindo conforto e encorajamento, permitindo reduzir a ansiedade e os níveis de estresse relacionados ao trabalho de parto, além de contribuir na prestação de apoio, diminuição do tempo e boa evolução do mesmo 7,14,21,22. Neste sentido, considera-se que o acompanhante desempenha um papel fundamental no processo de parto, como: estar presente, acalmar, transmitir força, encorajar e proporcionar apoio físico e emocional. Foi enfatizado que só de estarem próximos já é uma maneira de ajudar ${ }^{7,14,21}$.
Sabe-se que a presença do acompanhante é importante tanto em função de todo o apoio psicológico, físico e emocional prestado, quanto por colaborar juntamente com os profissionais de saúde na assistência prestada, ajudando-os e alertando a situações que podem mudar completamente a vivência da parturiente durante seu trabalho de parto.

Corroborando essa ideia, a OMS afirma que um dos principais parâmetros das boas práticas da assistência ao parto e nascimento, é como a presença do acompanhante pode influenciar na evolução do trabalho de parto e parto, por conta do vínculo que se cria naquele momento, do amparo e segurança ofertados, da ajuda com a aplicação das práticas não farmacológicas ${ }^{8}$.

É evidente que a presença do acompanhante diminui o risco de adversidades durante o parto, por proporcionar segurança à parturiente e apoio. Verificouse um resultado significativo quanto à aplicação da prática de humanização no trabalho de parto pelas enfermeiras, visto que elas incluem o acompanhante durante todo o processo, o que proporciona conforto, segurança e aumento da vinculação mãe-filho-paifamília durante esse período ${ }^{14,23}$.

Os profissionais de saúde precisam refletir que o acompanhante faz parte do processo e precisa ser incluído no mesmo, pois irá auxiliar e alertar nas queixas e necessidades expressadas pela parturiente. Também é importante ressaltar que o acompanhante deve ser escolhido a partir do desejo da mulher, não podendo haver preconceitos ou influência dos profissionais ou organizações sobre essa escolha. Ressaltase ainda, necessidade de que os profissionais de saúde precisam estar cientes de que não pode existir transferência do cuidado, pois é responsabilidade do profissional acompanhar a parturiente e auxiliar durante o seu processo parturitivo, tornando assim o acompanhante uma ponte no processo do cuidado.

Foi notório a importância da presença do acompanhante, sendo evidenciado que as enfermeiras e a organização de saúde respeitam a lei do acompanhante entendendo-o como facilitador de todo processo e sendo necessário para a formação do vínculo mãe-filho-pai-famíliaa ${ }^{14,15,21-23}$. 


\section{Estrutura Física e Recursos Materiais}

O parto passou de um processo natural para um sistema controlado, onde o local de nascimento mudou de domiciliar para a hospitalocêntrico. Com o intuito de resgatar esse processo natural, os hospitais abriram as salas de partos aos acompanhantes com o objetivo de torna-lo mais semelhante e acolhedor ao ambiente doméstico para proporcionar a satisfação materna, porém o lugar permaneceu mesmo, como também foi discutido pela $\mathrm{OMS}^{8}$.

Neste sentido, a OMS preconiza que um ambiente adequado é aquele onde a mulher tenha um atendimento de qualidade, que seja respeitado sua privacidade, com direito ao acompanhante de livre escolha e evitando a presença de pessoas que não são necessárias no momento do parto ${ }^{8}$.

Já a Rede Cegonha reforça que a humanização implica uma responsabilidade com a ambiência, sendo necessária uma adequação dos locais que realizam partos, entendendo o espaço físico como um ambiente social, profissional e interpessoal que irá propiciar uma atenção humanizada e acolhedora considerando questões biopsicossocioespirituais, melhorando as condições de trabalho para os profissionais e serviço para as usuárias. Vale ressaltar a necessidade de uma boa assistência visando a avaliação regular do bem-estar físico e emocional da mulher em paralelo com o local adequado para o parto ${ }^{2,8}$.

A estrutura inadequada e a carência de recursos materiais interferem na assistência que será prestada a gestante durante o trabalho de parto e parto, deixando as mulheres vulneráveis e os profissionais impedidos de agir, limitando o cuidado que irão prestar. Este aspecto foi observado nos estudos ${ }^{13,24,25}$ onde os profissionais relataram que a infraestrutura inadequada e falta de recursos materiais colaboram para uma assistência precária, no entanto. Dentre os estudos citados, Oliveira ${ }^{24}$ foi o único que evidenciou um discurso positivo em que os profissionais de enfermagem relataram que os partos eram feitos em quartos separados com biombo ou cortinas, cumprindo o que é proposto pela Rede Cegonha.

Sabe-se que a estrutura física influencia diretamente na assistência que será prestada as parturientes. A partir do momento que as enfermeiras têm um espaço no qual possam estimular o uso dos métodos não farmacológicos de alívio da dor, a autonomia, livre posicionamento, e privacidade, o parto irá evoluir de forma satisfatória e única para as mulheres, tornando a assistência humana e efetiva, respeitando os desejos e limites das mesmas $13,24,25$.

Logo, nota-se que essa escassez de materiais impacta não só no atendimento que será prestado, mas também na visibilidade negativa que a usuária tem do serviço. Sendo assim, percebe-se que essa ausência deixa as gestantes vulneráveis no processo de parto e limita a assistência das enfermeiras perante as usuárias.

\section{Relações de Poder}

As relações de poder no parto se apresentam em diferentes níveis hierárquicos, onde o médico ocupa o maior nível geralmente por conta da hegemonia médica e por acharem que possuem o maior conhecimento, sendo que suas imposições perpassam pelas enfermeiras e puérperas. Já as enfermeiras que se encontram no nível intermediário, impõem por muitas vezes o seu poder sobre as puérperas que consequentemente ficam na base dessa hierarquia, recebendo ordens tendo suas vontades anuladas e aceitando tudo que os profissionais de saúde decretam por acharem que os mesmos têm maior poder e conhecimento técnico-científico ${ }^{18,24}$.

Em 2002, a violência foi definida pela OMS como sendo o uso intencional da força física ou do poder, real ou em ameaça, contra si próprio ou outras pessoas, resultando ou podendo resultar em lesão, morte, dano psicológico, deficiência de desenvolvimento ou privação ${ }^{8}$. Desta forma, a relação de poder exercida entre os profissionais de saúde e para com as gestantes pode ser considerada uma violência, principalmente por gerar um dano psicológico, na maioria dos casos, em um momento que deveria ser único e especial na vida daquela mulher.

Destaca-se que o saber científico e a técnica adquiridos pelos profissionais favorecem de certa forma para a despersonalização da mulher nesse processo, ainda que esta mulher participe de todo momento parturitivo, essa participação é vista como uma relação de subordinação por contribuir com o trabaIho do profissional e não de uma forma autônoma. Portanto, a mulher sempre é vista como coadjuvante do processo e não como autora principal da ação, seu corpo é transformado em um objeto onde o profissional tem total autonomia sobre o mesmo ${ }^{2,18}$. 
Destarte, ressalta-se que existem limites estabelecidos pela hierarquia médico/enfermeiro, além do discurso hegemônico médico, no meio hospitalar, o que restringe e limita o espaço da enfermeira na assistência, principalmente nos partos de risco habitual. Esses fatores acabam desencadeando em práticas consideradas prejudiciais a mãe e recém-nascido, onde o desejo da mesma nunca é respeitado sendo o seu corpo manipulado de forma excessiva e trazendo danos psicológicos e emocionais que, muitas vezes, são irreparáveis ${ }^{24}$.

Os profissionais devem ter uma adesão cada vez maior para uma educação continuada, de forma construtiva e horizontal, podendo haver uma troca de saberes, empíricos e técnicos que perpassam desde os médicos, enfermeiras e equipe de enfermagem até as mulheres para que essas sejam instruídas e empoderadas que são protagonistas do seu processo de parto e os profissionais de saúde entendam que o seu papel é auxiliar e assistir as mulheres no seu processo ${ }^{18,19,26}$.

\section{Uso das Terapias não Farmacológicas}

O apoio prestado as mulheres pelas enfermeiras e pelo acompanhante de sua escolha durante todo o processo de parto é de extrema importância para suportarem a dor, diminuir a necessidade de analgesia farmacológica e tecnologias invasivas e consequentemente tornar melhor a experiência do parto. Além desse apoio, existem os métodos não farmacológicos de alivio da dor que são técnicas que iram auxiliar a parturiente no trabalho do parto e parto, tanto na evolução quando na diminuição da dor e causar menos efeitos colaterais para mãe e o bebê ${ }^{8}$.

Os métodos não farmacológicos são compostos por livre posicionamento e liberdade de adotar posições verticalizadas, presença do acompanhante de sua escolha, banho de chuveiro, imersão na água, uso da bola suíça, cavalinho, massagens ou toques, respiração rítmica e ofegante, comandos verbais, relaxamento, musicoterapia, acupuntura, ervas e aromaterapia com olhos perfumados, uso de calor e frio superficiais, controle da luminosidade (penumbra), dentre outros $2,7-9,14,16$. Percebeu-se os métodos mais adotados pelas enfermeiras foram o cavalinho, bola suíça, banho morno e deambulação $0^{7,14,16,19,23}$.
É importante salientar que os métodos não farmacológicos para o alivio da dor devem ser ofertados as parturientes desde sua admissão na unidade de saúde, sendo comprovada a efetividade em seu uso na condução do processo parturitivo. Destaca-se que são eficazes na redução do tempo do trabalho de parto, obtendo um melhor resultado perinatal, aumentando o vínculo mãe-bebê-pai-família, reduzindo as necessidades de intervenções, proporcionando que o parto suceda de forma fisiológica onde a muIher seja a personagem principal desse processo ${ }^{5,7,14}$. Além disso, a utilização dos mesmos é benéfica, na medida em que oferecem alternativas, medidas de conforto, onde os profissionais saibam em qual fase do trabalho de parto cada método pode ser inserido e desde que a mulher aceite utiliza-lo $0^{5,727}$.

Destaca-se que as organizações de saúde, seja maternidade ou centro de parto normal, devem dispor de materiais e estrutura física adequada para que esses métodos sejam aplicados de forma efetiva, além de que os profissionais de saúde precisam ter conhecimento técnico e científico, não só do que são, mas também dos tipos de métodos não farmacológicos.

Sendo também necessário, entender em qual estágio do parto os mesmos devem ser aplicados, explicar quais são os benefícios e observar a efetividade daquele método perante aquela mulher, levando em consideração as particularidades da mesma, pois se não forem explicados e aplicados da forma correta poderão acarretar em complicações e não adesão das parturientes $s^{3-5}$.

Ressalta-se que apropriar a saúde como valor de uso é padronizar na atenção o vínculo com as usuárias, comunicar-se com as mesmas e seus familiares. O que irá garantir os seus direitos e os colocará como atores desse sistema através de sua ação de controle social, assim como deve possibilitar condições melhores para que os profissionais executem seu trabalho ${ }^{25}$.

Sendo assim, reflete de forma impactante na assistência prestada às parturientes e as mesmas conseguem obter maior confiança no processo, sentindo-se no controle de suas ações e decisões sobre o seu próprio cuidado, reduzindo seus anseios e incertezas, além de suas dores, sensações físicas e emocionais tornando o processo de parir humanizado e com menos complicações, sendo essas físicas e/ou psicológicas. 


\section{Considerações finais}

Por meio desta Revisão Integrativa da Literatura, constatou-se que os estudos demonstram a relevância do saber técnico científico e da implementação das boas práticas da humanização no processo do parto, entendendo que a mulher é protagonista do mesmo e a equipe, a facilitadora. Percebeu-se a importância de ser informado às mulheres todos os benéficos e efeitos dos procedimentos e somente colocá-los em prática com o consentimento delas. Sendo necessário entender que o cuidado perpassa por todo o processo do parto desde a admissão da parturiente até a alta.

A partir das leituras dos artigos verificou-se como limitação a escassez de estudos com ampla abrangência das boas práticas de enfermeiras na assistência ao parto. Poucos artigos abordam intuições que adotam amplamente as boas práticas de atenção ao parto e nascimento recomendadas pelo Ministério da Saúde e Organização Mundial de Saúde, como o uso de métodos não farmacológicos no manejo da dor, presença do acompanhante durante o trabalho de parto e parto, o aleitamento materno e o contato pele a pele, dentre outros. No entanto, foi observado em outros estudos que as mulheres são colocadas em um lugar passivo durante o processo e os profissionais mantêm o seu status de autoridade, estabelecendo assim uma relação verticalizada e despersonalizada e também ficam expostas devido a uma estrutura inadequada e a falta de recursos materiais. Dessa maneira, as práticas de humanização se tornam fragmentadas, deixando essa mulher mais vulnerável.

Por conta disso, notou-se a necessidade de estudos que lancem luz aos aspectos relacionados ao planejamento, organização e reorganização dos serviços de saúde para garantir melhores condições de trabalho aos profissionais e assistência as parturientes. Para tanto, é necessário que as enfermeiras e os profissionais envolvidos no cuidado com as parturientes estejam sempre buscando atualizações e capacitações com base em evidências científicas para que possam estar aprimorando cada vez mais a assistência integral, qualificada e humanizada, não deixando que suas crenças, ideológicas, preconceitos, religiosidade interfiram nesse processo de cuidado.

Espera-se através desde estudo contribuir, de forma positiva, sobre a relevância da adesão das boas práticas de humanização no trabalho de parto e parto na formação acadêmica, para os profissionais e organizações de saúde, podendo colaborar com a maior conquista e qualidade no cuidado à mulher nesse contexto, favorecendo na redução de agravos e complicações relacionados a intercorrências nas condutas e diminuindo as taxas de morbimortalidade materno-infantil.

\section{Contribuição dos autores}

Bispo LS participou da elaboração do projeto, concepção, delineamento, pesquisa em base de dados, construção de tabela e quadros, tabulação, análise, redação, correção e encaminhamento do artigo. Novaes FS da elaboração do projeto, concepção, delineamento, tabulação, análise, redação do artigo. Pérez BAG participou da orientação para elaboração do projeto, delineamento, tabulação, análise e redação do artigo e correção do artigo.

\section{Conflitos de interesses}

Nenhum conflito financeiro, legal ou político envolvendo terceiros (governo, empresas e fundações privadas, etc.) foi declarado para nenhum aspecto do trabalho submetido (incluindo, mas não se limitando a subvenções e financiamentos, participação em conselho consultivo, desenho de estudo, preparação de manuscrito, análise estatística, etc.).

\section{Referências}

1. Moreira MADM, Lustosa AM, Dutra F, Barros EO, Batista JBV, Duarte MCS. Políticas públicas de humanização: revisão integrativa da literatura. Cien Saude Colet. 2015;20(10):3231-42. doi: $10.1590 / 1413-812320152010.10462014$

2. Ministério da Saúde. Gravidez, parto e nascimento com saúde, qualidade de vida e bem-estar. [Internet]. 2013. Disponível em: http://bvsms.saude.gov.br/bvs/publicacoes/gravidez_parto_ nascimento_saude_qualidade.pdf

3. Ministério da Saúde. Programa Humanização do Parto: Humanização no Pré-Natal e Nascimento. [Internet]. 2002. Disponível em: https://escoladaparentalidade.com.br/programade-humanizacao-no-pre-natal-e-nascimento-o-que-e/

4. Ramos WMA, Aguiar BGC, Conrad D, Pinto CB, Mussumeci PA. Contribuição da enfermeira obstétrica nas boas práticas da assistência ao parto e nascimento. J Res Fundam Care. 2018;10(1):173-9. doi: 10.9789/2175-5361.2018.v10i1.173-179

5. Andrade LFB, Rodrigues QP, Silva RCV. Boas Práticas na atenção obstétrica e sua interface com a humanização da assistência. Rev Enferm UERJ. 2017;25:e26442. doi: 10.12957/reuerj.2017.26442 
6. Proqualis. Simplificando o cuidado centrado na pessoa. O que todos devem saber sobre o cuidado centrado na pessoa. [Internet]. 2016. Disponível em: https://proqualis.net/sites/ proqualis.net/files/Simplificando-o-cuidado.pdf

7. Duarte MR, Alves VH, Rodrigues DP, Souza KV, Pereira AV, Pimentel MM. Tecnologias do cuidado na enfermagem obstétrica: contribuição para o parto e nascimento. Cogitare Enferm. 2019;24:e54164. doi: 10.5380/ce.v24i0.54164

8. Organização Mundial de Saúde. Maternidade Segura. Assistência ao Parto Normal: um guia prático. [Internet]. 1996. Disponível em : https://pesquisa.bvsalud.org/bvsms/resource/pt/ mis-9570

9. Organização Mundial de Saúde. Boas práticas de atenção ao parto e ao nascimento. [Internet]. 1996. Disponível em: http:// static.hmv.org.br/wp-content/uploads/2014/07/OMS-PartoNormal.pdf

10. Ministério da Saúde. Diretrizes Nacionais de Assistência Parto Normal. [Internet]. 2017. Disponível em: http://bvsms.saude. gov.br/bvs/publicacoes/diretrizes_nacionais_assistencia_parto_ normal.pdf

11. Griboski RA, Guilhem D. Mulheres e profissionais de saúde: o imaginário cultural na humanização ao parto e nascimento. Texto Context - Enferm. 2006;15(1):107-14. doi: 10.1590/S010407072006000100013

12. Mendes KDS, Silveira RCCP, Galvão CM. Revisão integrativa: método de pesquisa para a incorporação de evidências na saúde e na enfermagem. Texto Context - Enferm. 2008;17(4):758-64. doi: 10.1590/S0104-07072008000400018

13. Feijão LBV, Boeckmann LMM, Melo MC. Conhecimento de enfermeiras residentes acerca das boas práticas na atenção ao parto. Enferm Foco. 2017;8(3):35-9. doi: 10.21675/2357707X.2017.v8.n3.1318

14. Santana AT, Dias R, Felzemburgh M, Couto TM. Atuação de enfermeiras residentes em obstetrícia na assistência ao parto. Rev Bras Saúde Mater Infant. 2019;19(1):145-55. doi: 10.1590/1806-93042019000100008

15. Carvalho EMP, Amorim FF, Santana LA, Göttems LBD. Avaliação das boas práticas de atenção ao parto por profissionais dos hospitais públicos do Distrito Federal, Brasil. Cien Saude Colet. 2019;24(6):2135-45. doi: 10.1590/141381232018246.08412019

16. Medeiros RMK, Teixeira RC, Nicolini AB, Alvares AS, Corrêa ÁCP, Martins DP. Cuidados humanizados: a inserção de enfermeiras obstétricas em um hospital de ensino. Rev Bras Enferm. 2016;69(6):1091-8. doi: 10.1590/0034-7167-2016-0295

17. Dulfe PAM, Barcellos JG, Alves VH, Rodrigues DP, Pereira AV, Silva AG. A assistência obstétrica ao parto e nascimento na percepção das mulheres. Rev Enferm UFPE line. 2017;11(12):5402. doi: 10.5205/1981-8963-v11i12a22795p5402-5416-2017
18. Pedroso CNLS, López LC. À margem da humanização? Experiências de parto de usuárias de uma maternidade pública de Porto Alegre-RS. Physis Rev Saúde Coletiva. 2017;27(4):116384. doi: $10.1590 / \mathrm{s} 0103-73312017000400016$

19. Oliveira JDG, Campo TNC, Souza FMLC, Davim RMB, Dantas JC. Percepção de enfermeiros obstetras na assistência à parturiente. Rev Enferm UFPE. 2016;10(10):3868-75. doi: 10.5205/reuol.966787805-1-ED1010201619

20. Brasil, Ministério da Saúde. Lei no 11.108/05, de 7 de Abril. Altera a Lei no 8.080, de 19 de setembro de 1990, para garantir às parturientes o direito à presença de acompanhante durante o trabalho de parto, parto e pós-parto imediato, no âmbito do Sistema Único de Saúde - SUS. [Internet]. Brasília, DF: 2005. Disponível em: https://www2.camara.leg.br/legin/fed/lei/2005/lei11108-7-abril-2005-536370-publicacaooriginal-26874-pl.html

21. Souza SRRK, Gualda DMR. A experiência da mulher e de seu acompanhante no parto em uma maternidade pública. Texto Context Enferm. 2016;25(1):e4080014. doi: 10.1590/0104$\underline{0707201600004080014}$

22. Silva RDM, Lima LSV, Aquino DMF, Silva LXL, Silva $A B$, Vicente $C D$. Inserção do pai nas maternidades municipais do Recife: opnião dos técnicos e auxiliares de enfermagem. Enferm em Foco. 2017;8(4):54-8. doi: 10.21675/2357-707x.2017.v8.n4.1029

23. Andrade LO, Felix ESP, Souza FS, Gomes LOS, Boery RNSO. Práticas dos profissionais de enfermagem diante do parto humanizado. Rev Enferm UFPE Line. 2017;11(supl 6):2576-85. doi: 10.5205/reuol.9799-86079-1-RV.1106sup201712

24. Oliveira VJ. O sensível e o insensível na sala de parto: interdiscursos de profissionais de saúde e mulheres [dissertação]. Minas Gerais: Universidade Federal de Minas Gerais; 2016.

25. Ministério da Saúde. Caderno Humaniza SUS. Brasília; 2014. p. 467

26. Pérez BAG, Oliveira EV, Lago MS. Percepções de puérperas vítimas de violência institucional durante o trabalho de parto e parto: revisão integrativa. Rev Enferm Contemp. 2015;4(1):66-77. doi: 10.17267/2317-3378rec.v4i1.472

27. Katzer T. Métodos não farmacológicos para o alívio da dor: percepções da equipe multiprofissional no trabalho de parto e parto [trabalho de conclusão de curso]. Santa Cruz do Sul: Universidade de Santa Cruz do Sul; 2016. 